\title{
Visitas virtuais aos pacientes com Covid-19 internados em UTI: relato de experiência de uma assistente social
}

Virtual visits to patients with Covid-19 hospitalized in the ICU: experience report of a social worker

Visitas virtuales a pacientes con Covid-19 hospitalizados en la UCI: informe de experiencia de una trabajadora social

\author{
Deisy Mery Randon Villaca \\ ORCID: https://orcid.org/0000-0002-2610-3177 \\ Universidade Estadual do Oeste do Paraná, Brasil \\ E-mail: dmrandon@gmail.com \\ Daniela Prochnow Gund \\ ORCID: https://orcid.org/0000-0001-8047-2080 \\ Universidade Estadual do Oeste do Paraná, Brasil \\ E-mail: danielaprochnow@yahoo.com.br \\ Mariângela Monteiro de Melo Baltazar \\ ORCID: https://orcid.org/0000-0001-6395-9516 \\ Universidade Estadual do Oeste do Paraná, Brasil \\ E-mail: mmmwgb@uol.com.br
}

\begin{abstract}
Resumo
O presente trabalho tem como objetivo relatar a experiência de uma assistente social residente que fez parte da equipe multiprofissional de comunicação responsável por realizar visitas virtuais aos pacientes da UTI Covid-19 em um hospital universitário do oeste do Paraná. Pauta-se metodologicamente em um estudo descritivo, do tipo relato de experiência, que ocorreu entre os meses de junho de 2020 e setembro de 2021. Dessa forma, o texto discorre sobre as situações vividas pela equipe multiprofissional de comunicação, os procedimentos de segurança, a visitação virtual, os pacientes, as famílias, os desafios enfrentados e a perspectiva do Serviço Social sob a conjuntura apresentada. Conclui-se que, apesar das implicações estruturais, logísticas e sanitárias, a implementação das telechamadas foi um grande sucesso ao beneficiar a todos os seus envolvidos e servir de ferramenta para a execução tanto das diretrizes do Plano Nacional de Humanização (PNH) quanto da garantia dos direitos do usuário.
\end{abstract}

Palavras-chave: Visita virtual; UTI; Pandemia; Equipe de comunicação; Serviço social.

\begin{abstract}
This study aims to report the experience of a resident social worker who was part of the multidisciplinary communication team responsible for making virtual visits to patients in the Covid-19 ICU at a university hospital in the western of Paraná. It is methodologically based on a descriptive study, of the type experience report, which occurred between June 2020 and September 2021. Thus, the study discusses the situations experienced by the multidisciplinary communication team, security procedures, virtual visitation, patients, families, the challenges faced and the Social Work's perspective under the presented situation. It is concluded that, despite the structural, logistical and sanitary implications, the implementation of the telecalls was a huge success in benefiting everyone involved and serving as a tool for the execution of both the guidelines of the National Humanization Plan (NHP) and the guarantee of user's rights.
\end{abstract}

Keywords: Virtual visit; ICU; Pandemic; Communication team; Social work.

\section{Resumen}

Este estudio tiene como objetivo informar la experiencia de una trabajadora social residente que formó parte del equipo multidisciplinario de comunicación responsable de realizar visitas virtuales a pacientes en la UCI Covid-19 en un hospital universitario del oeste de Paraná. Se basa metodológicamente en un estudio descriptivo, del tipo de relato de experiencias, ocurrido entre junio de 2020 y septiembre de 2021. Así, el texto discute las situaciones vividas por el equipo multidisciplinario de comunicación, los procedimientos de seguridad, las visitas virtuales, los pacientes, las familias, los desafíos enfrentados y la perspectiva del Trabajo Social bajo la coyuntura presentada. Se concluye que, a pesar de las implicaciones estructurales, logísticas y sanitarias, la implementación de las telellamadas fue un gran éxito al beneficiar a todos sus actores y servir como herramienta para la ejecución tanto de los lineamientos del Plan Nacional de Humanización (PNS) como de la garantía de los derechos de los usuarios.

Palabras clave: Visita virtual; UCI; Pandemia; Equipo de comunicación; Trabajo social. 


\section{Introdução}

Em 11 de março de 2020, o diretor geral da Organização Mundial da Saúde (OMS), Tedros Adhanom Ghebreyesus, declarou a doença Covid-19 como uma pandemia (Organização Pan-Americana de Saúde [OPAS], 2020). Inicialmente detectada na cidade chinesa de Wuhan, a Covid-19 caracteriza-se como uma infecção respiratória causada pelo vírus SARSCoV-2, variando desde a contaminação sem sintomas (assintomática) até a ocorrência da síndrome respiratória aguda e potencial letalidade (Singhal, 2020).

No Brasil, o Ministério da Saúde constatou o primeiro caso da doença em 26 de fevereiro de 2020, na cidade de São Paulo (Governo do Brasil, 2020). Quase um mês depois, em 22 de março, a cidade de Cascavel, no Paraná, confirmou sua primeira infecção pelo novo coronavírus (Bonsere et al., 2021). Desde então, a dinâmica das Unidades Básicas de Saúde (UBS) e hospitais foi readequada a fim de abarcar a chegada dos novos pacientes e evitar a transmissão viral.

Em casos mais graves, o quadro de saúde dos infectados pode desenvolver-se em uma pneumonia e danificar os tecidos pulmonares, acarretando na falência respiratória progressiva e requisitando internação em Unidades de Terapia Intensiva (UTIs). Assim sendo, o aumento de números de leitos de UTI e a aquisição de aparelhos de ventilação foram algumas das medidas adotadas conforme o avanço da pandemia e as necessidades de cada região (Moreira, 2020).

Além disso, para reter a propagação do agente infeccioso dentro do ambiente hospitalar e na comunidade em geral, as visitas presenciais foram suspensas. Dessa forma, uma reformulação do contato paciente-família fez-se necessária e foram implantadas as visitas virtuais: chamadas de vídeo feitas pela equipe de saúde do hospital entre o internado na UTI Covid-19 e seus parentes.

O objetivo do presente trabalho é, portanto, relatar a experiência de uma assistente social residente que fez parte da equipe multiprofissional de comunicação responsável por realizar visitas virtuais aos pacientes da UTI Covid-19 em um hospital universitário da região oeste do Paraná.

\section{Metodologia}

Trata-se de um estudo descritivo, do tipo relato de experiência (Silva \& Menezes, 2005). Aborda a trajetória de uma assistente social cursante de uma residência multiprofissional e atuante na equipe de comunicação na UTI Covid-19 do Hospital Universitário do Oeste do Paraná (HUOP) localizado em Cascavel, no Paraná. As ações descritas neste estudo foram realizadas entre os meses de junho de 2020 e setembro de 2021 sob supervisão de uma assistente social concursada, mestre em serviço social e política social.

\section{Resultados e Discussão}

\subsection{Equipe multiprofissional de comunicação}

Em março de 2020, com o início da pandemia do novo coronavírus, os atendimentos aos afetados iniciaram no HUOP. O hospital possuía, inicialmente, uma estrutura física destinada a vítimas feridas gravemente com fogo: a ala de queimados. Entretanto, por ser referência da macrorregião oeste do Paraná, a nova situação epidêmica exigiu que o hospital universitário transformasse a unidade em uma UTI que atenderia especificamente os infectados com a Covid.

Foram 20 leitos reservados a tal propósito que, ao longo do tempo, aumentaram gradativamente, chegando ao ápice de 70 e depois retornando aos 50 .

Além da expansão do número de leitos, demais aparelhos precisaram ser adquiridos a fim de amparar a crescente demanda. Camas hospitalares, ventiladores mecânicos, oxigênio, monitores, bombas de infusão para medicação e dieta, entre outros equipamentos, foram solicitados e posteriormente disponibilizados pelo Ministério de Saúde e o Estado do Paraná. 
Com o espaço físico já reformulado para o tratamento dos novos pacientes, os desafios seguintes estavam relacionados à acolhida emocional dos mesmos e de suas respectivas famílias (Ministério da Saúde, 2013). A suspensão das visitas presenciais a fim de conter a propagação viral foi uma medida necessária, porém inédita e profunda no funcionamento do hospital e no âmbito psicológico de todos os envolvidos.

Portanto, a instituição teve de reinventar o contato família-paciente a fim de cumprir, simultaneamente, as normas vigentes de saúde num contexto de pandemia e a garantia de direito dos usuários do Sistema Único de Saúde (SUS) a visitas hospitalares, especialmente a dos internados na Unidade de Terapia Intensiva aos afetados pela Covid-19.

A alternativa encontrada, então, foi a implantação da visitação por meio digital. Tal medida passou a ser adotada em meados de junho de 2020 quando uma equipe de comunicação foi formada entre trabalhadores e estudantes residentes do hospital. O grupo contou com cerca de 30 profissionais de saúde das áreas de enfermagem, fonoaudiologia, medicina, nutrição, psicologia e serviço social que se voluntariaram a auxiliar.

Um grupo de mensagens foi montado utilizando o aplicativo de celular "Whatsapp" com a finalidade de organizar a realização das chamadas. A coordenadora da equipe era responsável por estipular as escalas dos dias e horários de atendimento atribuídas a cada participante, promovendo a rotatividade das tarefas e readequando a agenda conforme necessário.

A fim de assegurar a saúde dos voluntários, bem como a dos pacientes, a comissão de enfermagem de Controle de Infecção Hospitalar (CIH) ministrou cursos preparatórios acerca dos procedimentos a serem seguidos dentro de um ambiente com alto potencial infeccioso como a UTI Covid-19.

Foram repassadas instruções sobre a paramentação e desparamentação adequadas das vestimentas hospitalares, técnicas de higiene das mãos e dos materiais utilizados, manuseio das EPIs (Equipamentos de Proteção Individual), processo de desinfecção pós-exposição (banho) e descarte correto do aparato e demais lixo produzido. (Conselho Federal de Enfermagem [Cofen] \& Conselho Regional de Enfermagem [Coren], 2020).

\subsection{Procedimentos de segurança}

Por ser um vírus de transmissibilidade principalmente aérea, a proteção nas Unidades de Terapia Intensiva aos pacientes com Covid-19 requer o uso de trajes e apetrechos de proteção específicos (Medeiros, 2020). Por conseguinte, uma preparação prévia era necessária antes da iniciação das chamadas virtuais. Um quarto restrito no andar da UTI foi, assim, reservado especialmente para a paramentação dos comunicadores.

Primeiramente, as roupas comuns dos voluntários eram substituídas pelo pijama hospitalar. Os cabelos eram presos e cobertos por um gorro descartável. As máscaras utilizadas eram de modelo N95 ou PFF2, seguindo as recomendações sanitárias (Agência Nacional de Vigilância Sanitária [Anvisa], 2020). Mais um gorro descartável era colocado sobre a cabeça com o intuito de proteger os elásticos da máscara. As mãos eram higienizadas conforme protocolo e dois pares de luvas de procedimento eram colocados. Os calçados eram restritos ao setor e deveriam ser fechados e envolvidos totalmente pelo propé impermeável. Por fim, um avental também impermeável era ajustado sobre o pijama e os óculos de proteção eram postos, podendo ser trocados por protetor facial (Face Shield) dependendo da disponibilidade de cada utensílio.

A alta demanda de EPIs deixava a situação instável, já que a disponibilidade de tais equipamentos variava conforme a pandemia progredia. Desse modo, havia um registro do SESMT (Serviço Especializado em Engenharia de Segurança e em Medicina do Trabalho) acerca do uso e reutilização das máscaras pela equipe atuante na UTI Covid-19. Antes dos atendimentos, todos os profissionais assinavam o documento ao pegarem suas respectivas máscaras, contabilizando assim o número de protetores disponíveis.

Ainda acerca da escassez de EPIs, a orientação geral era de que, se possível, não houvesse a troca dos aparatos durante todo o período de visitação. Deste modo, eram evitadas idas ao banheiro e pausas para comer ou beber água, já que tais 
atividades requisitavam a troca completa ou parcial dos protetores pessoais.

Para barrar a transmissão do vírus via objetos, nenhum material portátil de dentro da UTI era levado para fora. Os aparelhos telefônicos utilizados nas chamadas eram deixados dentro da unidade, bem como uma ficha constando o nome dos pacientes e os números para contato de seus respectivos familiares. Se necessário fotografar, filmar ou enviar qualquer tipo de informação ou arquivo, esses eram feitos via eletrônica utilizando os celulares que ficavam restritos à UTI, nunca aparelhos pessoais.

Após a realização das visitas, eram realizados os procedimentos de desparamentação e desinfecção pós-exposição. A retirada das EPIs era seguida por um banho completo, incluindo os cabelos, e os equipamentos descartáveis e/ou que não poderiam mais ser reutilizados eram desprezados em lixo infectante hospitalar (Soares et al., 2021). Somente depois de terminado todo o processo era possível vestir as próprias roupas e retirar-se do setor da UTI.

\subsection{Visitação virtual}

As visitas virtuais entre os pacientes da UTI Covid-19 e seus familiares eram realizadas diariamente no período da tarde, inclusive aos domingos e feriados, intermediadas por membros da equipe de comunicação. Era utilizado o aplicativo digital "Whatsapp" através do recurso "chamada de vídeo" conectado à rede Wi-Fi do próprio hospital.

Para que a realização das visitas fosse possível, era necessária a autorização da família do internado. Logo, os atuantes de Serviço Social responsáveis pela UTI Covid-19 ligavam para os familiares a fim de verificar o interesse em participar das videochamadas.

As condições físicas do paciente (entubado, desacordado, com respirador, pronado etc) eram transmitidas com clareza nesse momento para que não houvesse um choque de realidade com seu estado de saúde no momento de reencontro digital.

Caso a família aceitasse, eram enviados por e-mail um termo de consentimento e outro de responsabilidade que proibia a gravação de vídeos e fotos durante as chamadas, mantendo sigilosos o nome e a imagem do usuário, visto que o mesmo não estava em condições de assentimento.

Depois de todas as regulamentações era possível iniciar a visitação. Não havia um horário marcado com os familiares nem uma ordem de atendimento, já que a situação na UTI era muito instável e o quadro clínico dos internados poderia mudar de forma súbita. Dessa maneira, os visitantes eram orientados a esperar a ligação entre 13h e 18h.

A duração das visitas variava conforme o número de pacientes e aparelhos telefônicos. No início dos atendimentos, quando haviam poucos smartphones, ou em momentos de alta lotação da UTI, as telechamadas duravam menos tempo. Em contrapartida, após a chegada de mais celulares e com a redução de internamentos era viável estender a interação.

Caso não fosse possível fazer a chamada de vídeo por motivo de força maior (paciente recebendo atendimento ou realizando procedimentos, piora no quadro de saúde, falhas de conexão etc), as famílias eram contatadas e, posteriormente, recebiam atualizações gerais do respectivo internado durante a ligação diária do médico intensivista vigente. Essa ligação era realizada especificamente pelo médico, não sendo responsabilidade da equipe de comunicação, e tinha a finalidade de informar detalhadamente sobre a evolução da saúde dos usuários.

Terminadas as visitas, o registro da videochamada e demais considerações necessárias eram lançados em TASY, um software de prontuário eletrônico dos pacientes.

\subsection{Pacientes}

No início da pandemia, o perfil recorrente e majoritário dos internados na Unidade de Terapia Intensiva era o de idosos acima dos 60 anos com algum tipo de comorbidade, como: obesidade, problemas cardíacos e/ou respiratórios, diabetes, entre outros (Mercês, Lima \& Neto, 2020). Entretanto, ao longo do tempo, a faixa etária passou a mudar: os mais velhos já 
vacinados deram lugar aos mais jovens ainda não imunizados.

A maioria dos pacientes estavam desacordados, sedados, intubados, com ventilação mecânica etc. Normalmente, antes de terem um agravo no quadro clínico e serem enviados à UTI, eles estavam na enfermaria Covid-19, área responsável por cuidar dos infectados com sintomas leves e em recuperação. Outros, ainda, vinham transferidos de demais hospitais da região já em estado grave. Ao apresentarem melhoras, eles eram extubados e voltavam para a enfermaria.

A reação dos usuários ao acordar depois da extubação era imprevisível. Alguns não recuperavam a consciência prontamente, muitas vezes agitados ou confusos, e precisavam de tempo para compreender o que havia acontecido. Outros, lúcidos e despertos, queriam atualizações sobre o período em que estiveram inconscientes. Perguntas sobre o próprio estado de saúde e o da família eram recorrentes, além de preocupações financeiras e acerca do trabalho.

O desejo de rever os entes queridos era grande e pôde ser minimizado através das visitas virtuais. O reencontro, mesmo que por uma tela de celular, era sempre especial e emocionante. Os familiares sentiam-se aliviados com a melhora do paciente e o mesmo, por sua vez, demonstrava ansiedade em voltar para casa. Era um momento de reconciliação e união.

Os usuários conscientes e capazes de falar muitas vezes conversavam com os profissionais. Durante as ligações, apresentavam sua rede familiar aos voluntários, contavam sobre suas vidas, suas rotinas, seus medos e sobre a saudade de pessoas e lugares.

Os agradecimentos à equipe também eram frequentes. Eles reconheciam a importância das chamadas de vídeo e elogiavam a atuação dos comunicadores. Outros pacientes não conseguiam falar por conta das consequências da intubação, mas o benefício da visitação era perceptível por meio de suas expressões e atitudes.

\subsection{Famílias}

Diversas eram as reações das famílias ao receberem a ligação do Serviço Social verificando o interesse pelas telechamadas. Algumas recusavam a proposta alegando ser uma situação muito impactante e que gostariam de receber apenas as informações do médico sobre a saúde do paciente. Outras, ainda, afirmavam que realizariam a chamada de vídeo quando o quadro clínico melhorasse. A maioria dos familiares, entretanto, aceitavam prontamente a oportunidade ofertada.

A quantidade de pessoas nas visitas variava muito: enquanto alguns preferiam privacidade neste momento, atendendo a ligação sozinhos, outros reuniam os moradores da casa em frente à tela ou adicionavam demais participantes por meio do recurso "chamada em grupo".

As atividades realizadas durante o contato também eram distintas e particulares de cada ambiente familiar. Ficar em silêncio, observar o paciente, rezar e praticar suas crenças, expor pensamentos positivos, torcer pela recuperação do internado, contar piadas ou fazer brincadeiras, mostrar os animais de estimação, tocar um instrumento ou cantar eram alguns dos feitos mais comuns.

As emoções despertadas iam desde a mais profunda tristeza, em casos com pouca ou nenhuma chance de recuperação, até a euforia ao receberem a notícia de melhora no quadro de saúde (Beccaria et al., 2008).

Além disso, as perguntas das famílias à equipe multiprofissional eram constantes. A mais frequente era sobre a capacidade de escuta e compreensão dos usuários desacordados. A orientação dada pelos psicólogos do hospital foi a de responder que, apesar de não ser possível saber se os pacientes conseguiam entender as falas, eles "ouviam com o coração".

Ademais, questões sobre a saúde e a melhora do enfermo eram frequentemente levantadas. Por não ter autorização ou competência para repassar atualizações médicas, os voluntários orientavam que tais dúvidas fossem retiradas na ligação com o médico.

Assim como os internados, as famílias também agradeciam os profissionais pelos serviços prestados. Muitos parentes de usuários que foram transferidos para o HUOP relatavam não haver esse meio alternativo de visitação nos demais hospitais. 
Alegavam que esse era um ótimo método de contato, ajudando a reduzir a ansiedade e preocupação causadas pela distância do familiar adoecido.

\subsection{Desafios enfrentados}

Inúmeros foram os desafios enfrentados pela equipe multiprofissional de comunicação. A inconsistência da pandemia acarretada pela flutuação no número de casos, internados e óbitos deixava os trabalhadores em constante estado de alerta e exigia que mudanças rápidas e eficientes fossem feitas sempre que necessário (Campos \& Canabrava, 2020).

Nesse sentido, um dos maiores impasses para a realização das visitas virtuais foi a falta de voluntários. Em momentos de superlotação da UTI, a coordenadora da equipe solicitava a adição de novas pessoas ao time de comunicadores e o aumento da carga horária daqueles que já estavam em atividade. Eventualmente, conforme foram contratados profissionais de atuação exclusiva aos afetados pela Covid-19, mais pessoas dispuseram-se a ajudar nos atendimentos.

A escassez de equipamentos foi outra problemática encontrada. No início, a pouca quantidade de aparelhos celulares e sua baixa qualidade, além de problemas de conexão com a internet, foram fatores que impediram a realização de chamadas de vídeo adequadas. Não era possível fazer várias ligações consecutivas por conta da rapidez com que a bateria dos telefones esgotava, atrasando o processo e deixando alguns pacientes sem a visita.

Conforme a pandemia avançava, entretanto, a importância desse contato digital foi sendo reconhecida e passou a receber atenção governamental. A Receita Federal enviou, por meio de doações, aparelhos em boas condições de uso e o hospital melhorou a rede Wi-Fi ofertada. Foi possível, então, aumentar a duração das telechamadas e atender mais usuários em menos tempo.

Conjuntamente aos empecilhos logísticos, o desgaste físico e emocional dos atuantes tornava a tarefa ainda mais difícil. Os Equipamentos de Proteção Individual eram desconfortáveis e sufocantes, a máscara apertava o rosto e as camadas de roupa abafavam o corpo. Era angustiante e exaustivo não poder descansar, ir ao banheiro, tomar água ou comer.

Não somente, a preocupação com as chances de adquirir o vírus, apesar de todos os equipamentos e medidas protetivas adotadas, deixava o psicológico dos comunicadores abalado e criava uma sensação de intensa vulnerabilidade (Sonis et al., 2020).

\subsection{Perspectiva do Serviço Social}

O papel do profissional do Serviço Social é a defesa dos direitos humanos (Conselho Federal de Serviço Social [CFESS], 1993). A subjetividade da sua atuação varia, porém, conforme o meio em que está inserido e suas particularidades.

Conforme Santos, Eleutério \& Lima (2015), o assistente social integrado num contexto hospitalar de UTI deve possibilitar a interação entre o usuário e seu meio familiar.

Entretanto, também disposto no Código de Ética do/a Assistente Social, infere-se que o capacitado deve “desempenhar suas atividades profissionais, com eficiência e responsabilidade, observando a legislação em vigor" (CFESS, 1993).

Portanto, a implantação das visitas virtuais num momento de pandemia foi uma providência extraordinária tomada com a finalidade de abarcar ambos os postulados anteriormente citados: tanto o direito do usuário de interagir com sua família quanto os decretos de saúde pública acerca das medidas de distanciamento social foram respeitados.

Outro aspecto intrínseco à atividade do assistente social é a empatia. Conforme Bracons (2019, p. 140):

"O Serviço Social é uma profissão que se ocupa do bem-estar das pessoas, grupos, comunidades e sociedade em geral e que utiliza a relação de ajuda como elemento central do seu desempenho. Ora, no âmbito desta relação, a empatia surge como um elemento imprescindível para entender, compreender e ajudar a pessoa." 
Não sendo somente uma característica requisitada pelos habilitados nessa área de atuação, mas também uma das diretrizes previstas na Política Nacional de Humanização (PNH) do SUS, a alteridade permeou toda a experiência das telechamadas (Ministério da Saúde, 2010). Muitas vezes, os anseios vividos pelos internados e seu círculo social compadeciam e afetavam sentimentalmente os voluntários que procuravam agir de maneira acolhedora.

As possibilidades de acalento, todavia, eram limitadas devido às restrições de higiene. Segundo Sonis et al. (2020), os EPIs e demais medidas de controle sanitário durante a pandemia de Covid-19 afastaram tanto física quanto emocionalmente os profissionais de saúde dos pacientes e familiares. O desafio de promover, então, o conforto requisitado pelos atendidos ia de encontro à necessidade de autopreservação dos atendentes.

No HUOP, uma forma de contornar tal impasse foi a utilização de crachás com nome e foto de cada participante da equipe de comunicação. Assim, os usuários e seus parentes podiam conhecer o rosto daqueles que os atendiam, tornando o processo de cuidado mais pessoal. O sentimento de grupalidade e acolhimento também era despertado entre os próprios trabalhadores, gerando um apoio psicológico mútuo a fim de enfrentar as tribulações do ofício (Ministério da Saúde, 2010).

Além do afastamento entre profissional e paciente, a distância na relação do usuário com sua rede de apoio foi outra adversidade observada. A impossibilidade de contato direto durante o período de internamento afetava as famílias psiquicamente, em especial nos momentos precedentes ao óbito do ente querido. De acordo com Garrido \& Rodrigues (2020), a interrupção das práticas religiosas e funerárias acarretadas pela pandemia afligiu psicologicamente os enlutados.

Dessa forma, as visitas virtuais, apesar de não substituírem a presença física, possibilitaram que os familiares realizassem seus ritos e crenças à distância, promovendo um último encontro com o enfermo.

Por fim, a gratidão demonstrada pelos pacientes recuperados e sua rede familiar era imensa. Apesar de não ser possível trocar abraços ou apertos de mão, as novas formas de agradecimento emocionaram os profissionais com a mesma intensidade (Fishman, 2020). Mensagens nas redes sociais, cartas e bilhetes, faixas em frente ao hospital, presentes e lembranças, dentre outros, expressavam o alívio e a felicidade vividos pelos usuários, valorizando a dedicação da equipe e trazendo esperança em um momento tão desafiador.

\section{Considerações Finais}

Constatou-se, por fim, a importância das visitas virtuais para a reaproximação entre família e paciente através da equipe voluntária de comunicação no contexto de pandemia de Covid-19. Essa medida inédita mostrou-se bem sucedida em fortalecer os vínculos afetivos, diminuir a ansiedade causada pelo distanciamento social e servir de ferramenta para a execução das diretrizes do Plano Nacional de Humanização (PNH) do SUS.

Apesar dos desafios estruturais, logísticos e sanitários, bem como as implicações dos Equipamentos de Proteção Individual (EPIs) e demais diligências, a implementação das telechamadas na UTI Covid-19 foi um grande sucesso e beneficiou a todos os seus envolvidos. Essa prática possibilitou um cuidado pessoal e participativo, promovendo o exercício da empatia por parte dos profissionais, assegurando o bem-estar dos atendidos e viabilizando a despedida da família em situações de óbito iminente do enfermo.

Ademais, o objetivo do presente trabalho foi cumprido ao relatar a experiência de uma assistente social residente que fez parte da equipe multiprofissional de comunicação na UTI Covid-19 em um hospital universitário do oeste do Paraná. Nesse sentido, os direitos do usuário assegurados pelo Serviço Social foram exercidos e garantidos simultaneamente ao cumprimento das ordens de controle epidemiológico decretadas pelos órgãos de saúde competentes.

Visto o posto, a visitação via chamadas digitais continuará a ser aplicada nas Unidades de Terapia Intensiva (UTIs) do HUOP após a pandemia, sofrendo adaptações conforme necessário. Parentes e amigos distantes ou impossibilitados de comparecer ao hospital poderão, assim, manter o contato com seus entes queridos internados. Essa técnica não tem, entretanto, 
a finalidade de substituir as visitas presenciais, mas sim coexistir com a já tradicional forma de interação, trazendo um meio alternativo viável para todas as partes.

\section{Referências}

Agência Nacional de Vigilância Sanitária - Anvisa. (2020). Nota Técnica GVIMS/GGTES/ANVISA nº 04/2020. Orientações para serviços de saúde: medidas de prevenção e controle que devem ser adotadas durante a assistência aos casos suspeitos ou confirmados de infecção pelo novo coronavírus (SARS-CoV-2) atualizada em 25/02/2021. https://www.gov.br/anvisa/pt-br/centraisdeconteudo/publicacoes/servicosdesaude/notas-tecnicas/nota-tecnica-gvims_ggtes_anvisa04_2020-25-02-para-o-site.pdf.

Bartoszko, J. J., Farooqi, M. A. M., Alhazzani, W., \& Loeb, M. (2020). Medical masks vs N95 respirators for preventing COVID-19 in healthcare workers: A systematic review and meta-analysis of randomized trials. Influenza and other respiratory viruses, 14(4), 365-373. https://dx.doi.org/10.1111\%2Firv.12745.

Beccaria, L. M., Ribeiro, R., Souza, G. L., Scarpetti, N., Contrin, L. M., Pereira, R. A. M., \& Rodrigues, A. M. S. (2008). Visita em Unidades de Terapia Intensiva: concepção dos familiares quanto à humanização do atendimento. Arq. ciênc. saúde;15(2):65-69. https://repositorio-racs.famerp.br/racs_ol/vol-152/id\%20263.pdf.

Bonsere, W. C. P., Alcides, M. A. R., Paetzold, M. G., Martinez, A. de C., Fleminge, A. G., Silva, L. W. F. da. (2021). COVID -19: um histórico inicial de casos no município de Cascavel - PR. Rev. Saúde Pública Paraná; 4(1): 65-76. https://doi.org/10.32811/25954482-2021v4n1p65.

Bracons, H. (2019). Empatia e Relação no Serviço Social que desafios para a profissão. Intervenção Social, (49/50), 135-144. http://revistas.lis.ulusiada.pt/index.php/is/article/view/2658.

Campos, F. C. C. de., \& Canabrava, C. M. (2020). O Brasil na UTI: atenção hospitalar em tempos de pandemia. SciELO Brasil, Saúde debate 44 (spe4). https://doi.org/10.1590/0103-11042020E409.

Conselho Federal de Enfermagem - Cofen, \& Conselho Regional de Enfermagem - Coren. (2020). Orientações Sobre A Colocação E Retirada Dos Equipamentos De Proteção IndividuaL (EPIs). http://www.cofen.gov.br/wp-content/uploads/2020/03/cartilha_epi.pdf.

Conselho Federal de Serviço Social - CFESS. (1993). Código de Ética do/a Assistente Social, Lei 8662/93. http://www.cfess.org.br/arquivos/CEP_CFESSSITE.pdf.

Fishman, M. (2020). The Silver Linings Journal: Gratitude During a Pandemic. Journal of radiology nursing, 39(3), 149-150. https://doi.org/10.1016/j.jradnu.2020.05.005.

Garrido, R. G., \& Rodrigues, R. C. (2020). Restrição de contato social e saúde mental na pandemia: possíveis impactos das condicionantes sociais. J. Health Biol Sci. 2020;8(1):1-9. http://dx.doi.org/10.12662/2317-3325jhbs.v8i1.3325.p1-9.2020.

Governo do Brasil. (2020). Brasil confirma primeiro caso do novo coronavírus. https://www.gov.br/pt-br/noticias/saude-e-vigilancia-sanitaria/2020/02/brasilconfirma-primeiro-caso-do-novo-coronavirus.

Medeiros, E. A. S. (2020). A luta dos profissionais de saúde no enfrentamento da COVID-19. SciELO Brasil, Acta Paul Enferm 33. https://doi.org/10.37689/acta-ape/2020EDT0003.

Mercês, S. O. das., Lima, F. L. O., \& Neto, J. R. T. de V. (2020). Association of COVID-19 with: age and medical comorbidities. Research, Society and Development, v. 9, n. 10, p. e1299108285. https://doi.org/10.33448/rsd-v9i10.8285.

Ministério da Saúde. (2010). HumanizaSUS: Documento base para gestores e trabalhadores do SUS. https://bvsms.saude.gov.br/bvs/publicacoes/humanizasus_documento_gestores_trabalhadores_sus.pdf.

Ministério da Saúde. (2013). HumanizaSUS: Política Nacional de Humanização - PNH. https://bvsms.saude.gov.br/bvs/publicacoes/politica_nacional_humanizacao_pnh_folheto.pdf.

Ministério da Saúde. (2021). O que é a Covid-19? https://www.gov.br/saude/pt-br/coronavirus/o-que-e-o-coronavirus.

Moreira, R. da S. (2020). COVID-19: unidades de terapia intensiva, ventiladores mecânicos e perfis latentes de mortalidade associados à letalidade no Brasil. SciELO Brasil, Cad. Saúde Pública 36 (5). https://doi.org/10.1590/0102-311X00080020.

Organização Pan-Americana de Saúde - OPAS. (2020). COVID-19 (doença causada pelo novo coronavírus): Folha Informativa. https://www.paho.org/bra/index.php?option=com_content \& view=article\&id=6101:covid19\&It.

Santos, N. C., Eleutério, A. P. da S., \& Lima, R. L. (2015). O fazer profissional do/a Assistente Social na Unidade de Terapia Intensiva do HUOL: uma análise sob o olhar dos usuários. Serviço Social em revista. Londrina, 17(2),.146-168. http://dx.doi.org/10.5433/1679-4842.2015v17n2p146.

Silva, E. L. da., \& Menezes, E. M. (2005). Metodologia da pesquisa e elaboração de dissertação. (4. ed. rev. atual.). Florianópolis: UFSC. https://tccbiblio.paginas.ufsc.br/files/2010/09/024_Metodologia_de_pesquisa_e_elaboracao_de_teses_e_dissertacoes1.pdf

Singhal T. (2020). A Review of Coronavirus Disease-2019 (COVID-19). Indian journal of pediatrics, 87(4), 281-286. https://doi.org/10.1007/s12098-02003263-6.

Soares A. K. T., Arruda F. R., Novais G. M. de M. L., Martins R. B., \& Araújo A. H. I. M. de. (2021). A importância da paramentação e desparamentação seguras em infecções por aerossol, com foco à Covid-19: uma revisão da literatura. Revista Eletrônica Acervo Saúde, 13(6), e7786. https://doi.org/10.25248/reas.e7786.202. 
Research, Society and Development, v. 10, n. 17, e238101724743, 2021

(CC BY 4.0) | ISSN 2525-3409 | DOI: http://dx.doi.org/10.33448/rsd-v10i17.24743

Sonis, J. D., Kennedy, M., Aaronson, E. L., Baugh, J. J., Raja, A. S., Yun, B. J., \& White, B. A. (2020). Humanism in the Age of COVID-19: Renewing Focus on Communication and Compassion. Western Journal of Emergency Medicine: Integrating Emergency Care with Population Health, 21(3). http://dx.doi.org/10.5811/westjem.2020.4.47596. 